\title{
Padronização da técnica imunoenzimática do ELISA de captura, no sistema avidina-biotina para a identificação de sangue ingerido por Lutzomyia (Lutzomyia) longipalpis (Lutz \& Neiva, 1912)
}

\author{
Enzyme-linked Immunosorbent Assay biotin/avidin method standardization, for \\ identification of Lutzomyia (Lutzomyia) longipalpis \\ bloodmeals (Lutz \& Neiva, 1912)
}

\author{
Ana Maria Marassá ${ }^{\text {, Cleide Aschenbrenner Consales }}{ }^{2}$ \\ e Eunice Aparecida Bianchi Galati ${ }^{3}$
}

\begin{abstract}
RESUM0
Aidentificação de sangue ingerido pelos insetos é um importante parâmetro para elucidar aspectos ligados à transmissão de zoonoses, dentre elas, as leishmanioses. Dos métodos empregados para esclarecer a atração de vetores por animais que possam atuar como reservatórios dessas parasitoses, destacam-se os imunológicos. 0 estudo teve como objetivo, padronizar a técnica imunoenzimática de captura e titular amostras de sangue ingerido em fêmeas de flebotomíneos ingurgitadas de Lutzomyia longipalpis criadas em laboratório e alimentadas experimentalmente em rato. Em vista da alta sensibilidade, favorecida pelo sistema avidina-biotina, foi possível a realização de pelo menos noventa testes, de cada uma das amostras em duplicata, e constatar a presença de sangue para todas as amostras com períodos de 12 e 24 horas pós-ingestão, observando-se diferença significativa entre os respectivos títulos.

Palavras-chaves: Identificação de sangue ingerido. Lutzomyia longipalpis. Flebotomíneos. Técnica imunoenzimática de captura. Vetores.
\end{abstract}

\begin{abstract} assay. Vectors.

0 padrão alimentar em flebotomíneos faz parte de um conjunto de informações necessárias para 0 entendimento e avaliação epidemiológica do comportamento de espécies em áreas de transmissão de leishmanioses. Pode ser considerado como indicador, em determinados ambientes, dos possíveis
\end{abstract}

Bloodmeals taken by insects constitute an important parameter for clarifying aspects of the transmission of zoonoses, including leishmaniases. Immunological assays can be used to investigate the attraction of vectors to animals, which may be hosts of these parasitoses. The objective of this study was to standardize a sandwich enzyme-linked immunosorbent assay and titer samples with different time periods of digestion, in laboratory-bred Lutzomyia longipalpis fed on rats. In the light of the high sensitivity that the biotin-avidin method permits, the technique provided at least ninety repeat tests for each sample and identified recent bloodmeals taken by these insects. Bloodmeals were detectable up to 12 and $24 \mathrm{~h}$ after blood ingestion, and a significant difference between these titers was observed.

Key-words: Blood meal identification. Lutzomyia longipalpis. Phlebotominae. Sandwich enzyme-linked immunosorbent

animais que estejam participando na manutenção do ciclo enzoótico, além de possibilitar a identificação do reservatório.

Diversas metodologias são empregadas na pesquisa de hábito alimentar de flebotomíneos e dentre elas, destacam-se observações visuais, capturas com isca humana, armadilhas

1. Instituto Adolfo Lutz, São Paulo, SP. 2. Instituto Pasteur, São Paulo, SP. 3. Departamento de Epidemiologia da Faculdade de Saúde Pública da Universidade de São Paulo, São Paulo, SP

Apoio financeiro: Fundação de Amparo à Pesquisa do Estado de São Paulo (FAPESP) - projeto 00/06811-0.

Endereço para correspondência: Dra. Ana Maria Marassá. Laboratório de Parasitoses Sistêmicas. Instituto Adolfo Lutz. Av. Dr. Arnaldo 355 01246-902 São Paulo, SP.

Tel: 11 3068-2891.

Recebido para publicação em 28/10/2003

Aceito em 4/8/2004 
contendo iscas animais, encontro em abrigos de animais silvestres e domésticos e técnicas imunológicas. Entretanto, a maioria dos estudos que objetivam a investigação do comportamento alimentar desses insetos, tem como enfoque a utilização de iscas animais ${ }^{367}$.

As técnicas imunológicas para detecção de sangue ingerido em artrópodes têm sido utilizadas desde os primórdios de 1900, quando King e Bull ${ }^{10}$, Rice e Barber ${ }^{17}$ adaptaram a técnica de precipitina para determinar a fonte alimentar em mosquitos e outros insetos.

A técnica imunoenzimática foi inicialmente desenvolvida para 0 diagnóstico de pacientes portadores de malária ${ }^{22}$, sendo posteriormente adaptada para 0 estudo do hábito alimentar de culicídeos². Dessa maneira, diversas modalidades do método foram introduzidas, dependendo particularmente da concentração de sangue ingerido, contido nas amostras e das informações que se deseja obter no estudo $0^{1318} 19$.

Diferentes autores empregaram a técnica imunoenzimática para 0 conhecimento de fonte alimentar em flebotomíneos ${ }^{512} 24$. Entretanto, com 0 estabelecimento da técnica imunoenzimática de captura, foi possível detectar nas amostras diluídas de diferentes espécies de vetores, a presença de sangue ingerido em pequenas concentrações, tais como, as encontradas em pequenos dípteros das famílias Ceratopogonidae e Psychodidae que ingerem, em média, 0,01 a 0,1 e 0,01 a 0,3mg de sangue, respectivamente, bem como evidenciar mais de um repasto efetuado em diferentes fontes alimentares ${ }^{20}$.

Quinnel e cols ${ }^{16}$, em estudos realizados no Estado do Pará, empregaram 0 teste imunoenzimático de captura ${ }^{20}$, para identificar 0 sangue ingerido em fêmeas de Lutzomyia longipalpis alimentadas em hospedeiros conhecidos, com o objetivo de verificar experimentalmente a preferência alimentar. Colmenares e cols $s^{4}$, também utilizando a mesma técnica, empregando o sistema peroxidase avidina-biotina, estudaram o comportamento alimentar de Phlebotomus perniciosus Newstead 1911, em quatro diferentes áreas geográficas na Espanha .

Neste estudo, a opção pelo teste imunoenzimático de captura utilizando o sistema fosfatase alcalina avidina-biotina justifica-se por: adicionar dados relativos à capacidade vetorial, devido a sua sensibilidade e especificidade, pois cada molécula de avidina apresenta quatro sítios de ligação com a biotina, sendo esta, uma vitamina que pode ser conjugada facilmente a moléculas de alto ou baixo peso molecular, sem que ocorra perda de sua atividade biológica e que, por sua vez, apresenta elevada interação com a avidina ${ }^{8}$; somente 0 sistema peroxidase avidina-biotina ter sido empregado na identificação de repasto sanguíneo de flebotomíneos4; permitir a identificação de sangue ingerido em amostras com diferentes períodos de pós-ingestão; - utilizar a enzima fosfatase alcalina, por ser mais estável em condições de armazenagem e em circunstâncias onde condições estéreis não possam ser mantidas ${ }^{25}$, permitir uma grande diluiçãa $0^{15} \mathrm{e}$ identificar a fonte alimentar não somente de flebotomíneos, como de outros vetores.

\section{MATERIAL E MÉTODOS}

Amostras. Para a padronização da técnica, foram utilizados sessenta exemplares de flebotomíneos da espécie Lu. longipalpis, procedentes de colônia do Instituto Evandro
Chagas, Belém, Pará, criados no Laboratório de Entomologia do Departamento de Epidemiologia da Faculdade de Saúde Pública da Universidade de São Paulo (FSP/USP) . As larvas foram mantidas em placas com fundo de gesso e receberam alimentação adequada ao ambiente laboratorial, constituída por macerado contendo fezes desidratadas de coelho, terra e alimento utilizado para peixes ornamentais (Alcon ${ }^{\circledR}$, Brasil) até a fase de pupa. Após os adultos emergirem, foram separados trinta machos e trinta fêmeas, sendo estas, alimentadas em rato (Ratus ratus) , e os machos em solução de $\mathrm{H}_{2} \mathrm{O}$ e açúcar a $10 \%$. Os exemplares adultos foram mantidos em temperatura ambiente de $25^{\circ} \mathrm{C} \pm 2^{\circ} \mathrm{C}$.

Das fêmeas, foram retiradas a cabeça e genitália, sendo 0 tórax e abdome acondicionados em microtubos e conservados em freezer a $-20^{\circ} \mathrm{C}$, até 0 momento da dosagem, 5 a 6 meses após, tempo este semelhante ao utilizado por outros autores.

Preparo das amostras. 0 tórax e abdome dos exemplares foram macerados em 200 $\mu$ l de solução PBS-BSA ( A7030, Sigma, USA) $0,1 \%$ e a seguir centrifugados a $12.000 \mathrm{rpm}$, por 5 minutos e os sobrenadantes acondicionados a $-20^{\circ} \mathrm{C}$. Para 0 controle positivo do teste, foram coletados $10 \mathrm{ml}$ do sobrenadante de cada uma das trinta amostras de fêmeas ingurgitadas e a seguir acondicionados em freezer a $-20^{\circ} \mathrm{C}$.

Para 0 controle negativo do teste, foram coletados $10 \mathrm{ml}$ do sobrenadante de cada uma das trinta amostras de machos e acondicionados da mesma maneira que 0 controle positivo.

Padronização do teste. Microplacas de 96 cavidades (Nunc ${ }^{\circledR}$, Maxisorp, Denmark) foram sensibilizadas com $50 \mu \mathrm{l} /$ cavidade de soro total anti-rato (R-5256, Sigma, USA) em duplicata, nas concentrações de $20 \mu \mathrm{g} / \mathrm{ml}, 10 \mu \mathrm{g} / \mathrm{ml}, 5 \mu \mathrm{g} / \mathrm{ml}$, $2,5 \mu \mathrm{g} / \mathrm{ml}, 1,25 \mu \mathrm{g} / \mathrm{ml}$ e 0,625 $\mu \mathrm{g} / \mathrm{ml}$ diluídas em PBSe incubadas a $4^{\circ} \mathrm{C}$ por 18 horas. Após este período, as placas foram lavadas com PBS-Tween20 ( P-1379, Sigma, USA) por cinco vezes e os sítios livres, bloqueados com $200 \mu \mathrm{l} /$ cavidade de PBS-BSA $1 \%$, por 3 horas à temperatura ambiente.

Após este período, e a cada etapa da reação, foram realizadas lavagens, como já mencionado, sendo a seguir adicionados $50 \mu \mathrm{l} /$ cavidade do tampão PBS-BSA $0,1 \%$ das trinta fêmeas ingurgitadas em duplicata nas diluições de $1: 50,1: 100,1: 200,1 ; 400,1: 800,1: 1600$ e $1: 3200$ e as microplacas incubadas a $4^{\circ} \mathrm{C}$ por 18 horas.

A seguir, acrescentou-se $50 \mu \mathrm{l} /$ cavidade de IgG anti-rato biotinilado (B7139, Sigma, USA) nas concentrações de $2 \mu \mathrm{g} / \mathrm{ml}$, $4 \mu \mathrm{g} / \mathrm{ml}$ e $8 \mu \mathrm{g} / \mathrm{ml}$ e as microplacas foram incubadas por uma hora à temperatura ambiente. Após a incubação e lavagem, foram adicionados 50 $\mathrm{\mu l} /$ cavidade de avidina-fosfatase alcalina (A7294, Sigma, USA), nas diluições de 1:10.000, 1:30.000 e 1:40.000, permanecendo por mais uma hora à temperatura ambiente.

Como última etapa, foram adicionados $50 \mu \mathrm{l} /$ cavidade do substrato P-nitrophenil-phosphatase disodium ( Sigma \#104-105) na concentração de $1 \mu \mathrm{g} / \mathrm{ml}$ diluído em tampão dietanolamina (Merck) $10 \%$. A reação foi interrompida após 20 minutos, com adição de $100 \mu$ l de $\mathrm{NaOH} 3 \mathrm{~N} /$ cavidade e a leitura realizada em leitor de ELISA (Multiskan ${ }^{\circledR}$ EX) em comprimento de onda $405 \mathrm{~nm}$. 
Após a padronização da técnica, cada uma das trinta amostras foi processada em duplicata, para 0 estabelecimento do título de sangue ingerido por flebotomíneos, tendo sido adicionados em cada microplaca controles positivo e negativo, a fim de se evitar variações nos valores de absorbância, que podem interferir na significância do teste, quando as microplacas não são lidas logo após a adição do substrato. Para o cálculo das trinta amostras de Lu longipalpis, foram computados todos os valores de absorbância e os títulos de sangue ingerido foram expressos como $\log _{2}$ da recíproca da maior diluição das amostras apresentando reação positiva.

Capacidade da técnica em identificar a fonte de alimentação. Para este estudo, foram separadas outras trinta fêmeas ingurgitadas, processadas separadamente e subdivididas em grupos de 15 exemplares cada, sendo estabelecidos dois diferentes horários para a quantificação de sangue ingerido.

Os exemplares foram mantidos em insetário à temperatura ambiente e sacrificados em períodos de aproximadamente $12 \mathrm{e}$ 24 horas pós-ingestão, sendo então, realizada a técnica imunoenzimática de captura com a adição a cada microplaca das amostras a serem testadas em duplicata os respectivos controles positivo e negativo.

Para 0 cálculo do índice de positividade das amostras foram determinadas as médias em $\log _{2}$, desvios padrão, variâncias e também para a titulação de sangue ingerido nos horários préestabelecidos pós-ingestão, os resultados foram analisados pelo teste t de Student $₫$, ao nível de significância $1 \%(p<0,001)$.

\section{RESULTAD0S}

Para a identificação da concentração ideal do anti-soro de rato, para a sensibilização da microplaca, foi realizada uma titulação em bloco, variando-se as concentrações do anti-soro frente a diferentes diluições das amostras que compõem 0 controle positivo, em duplicata. A menor concentração do antisoro a ser utilizada na reação foi determinada como sendo $0,625 \mu \mathrm{g} / \mathrm{ml}$ ( Figura 1).

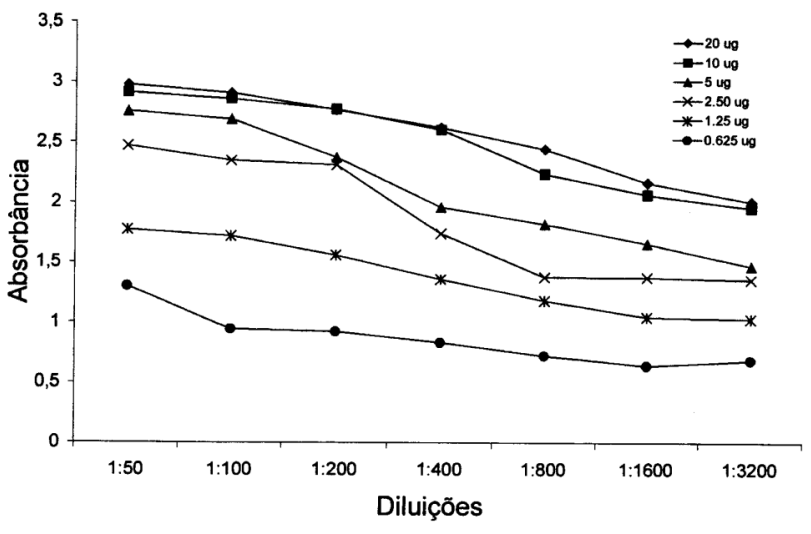

Figura 1 - Determinação da concentração ideal do anti-soro de rato para o ensaio imunoenzimático de captura na identificação de sangue ingerido por Lutzomyia longipalpis.
A seguir, foi determinada a menor concentração do segundo anticorpo, sendo estabelecido $8 \mu \mathrm{g} / \mathrm{ml}$ (Figura 2) e também foram testadas diferentes diluições de avidinafosfatase alcalina, sendo a diluição de 1:40.000 considerada como a que mais se adequou à reação (Figura 3) .

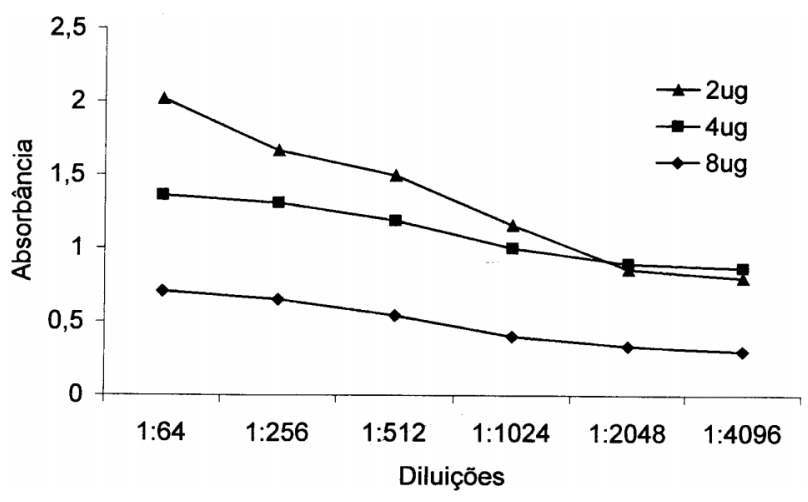

Figura 2 - Determinação da menor concentração do 20 anticorpo frente a diferentes diluições das 30 amostras de Lutzomyia longipalpis.

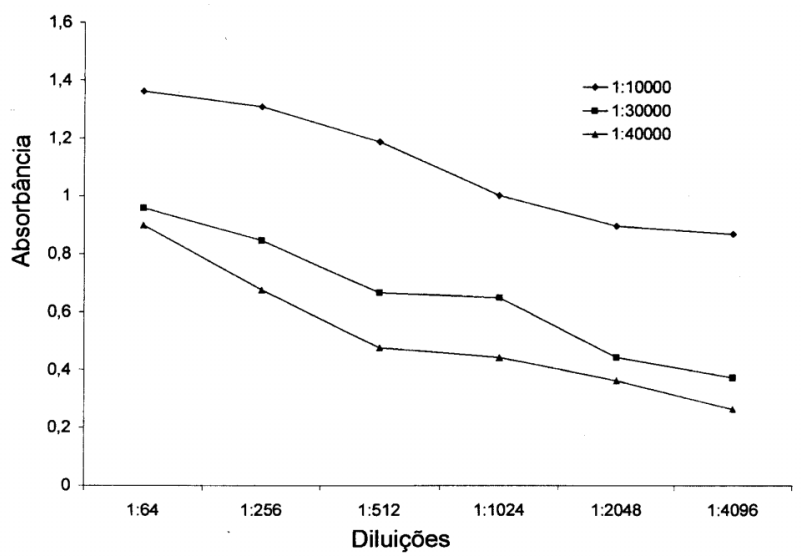

Figura 3 - Determinação da diluição ideal de avidina-fosfatase alcalina para o ensaio imunoenzimático (ELISA) de captura para identificação de sangue ingerido por Lutzomyia longipalpis.

Das diferentes diluições das amostras testadasna razão 2, a menor diluição para exemplares de flebotomíneos, contendo em torno de dois a quatro quartos de sangue no conteúdo abdominal, foi de 1:256.

0 ponto de corte da reação foi estipulado pelo emprego de três vezes 0 desvio padrão das amostras, sendo a absorbância específica igual ou maior que 0,261 considerada como valor positivo. A média do branco foi 0,082 com desvio padrão de 0,0065.

A média dos títulos de sangue ingerido para as trinta amostras foi $13,12 \log _{2}$ com desvio padrão de 0,084 e as médias determinadas para os grupos controle positivo enegativo das amostrastestadas foram $12,2 \log _{2}$ e $1 \log _{2}$, respectivamente. Os resultados referentes às trinta amostras utilizadas no estabelecimento da técnica para a titulação de sangue ingerido encontram-se representados na Figura 4.

Os resultados da dispersão das amostras de 12 horas e 24 horas pós-ingestão estão representados nas Figuras 5 e 6 e as respectivas médias, desvios padrão e variâncias foram $11,3 \log _{2} ; 0.09$ e 0,0081 para amostras de 12 horas e 10 $\log _{2} ; 0,16$ e 0,0256 para amostras de 24 horas.

Para os grupos com períodos de 12 e 24 horas pós-ingestão, verificou-sediferença significativa entre os títulos $(t=65 ; p<0,001)$. 


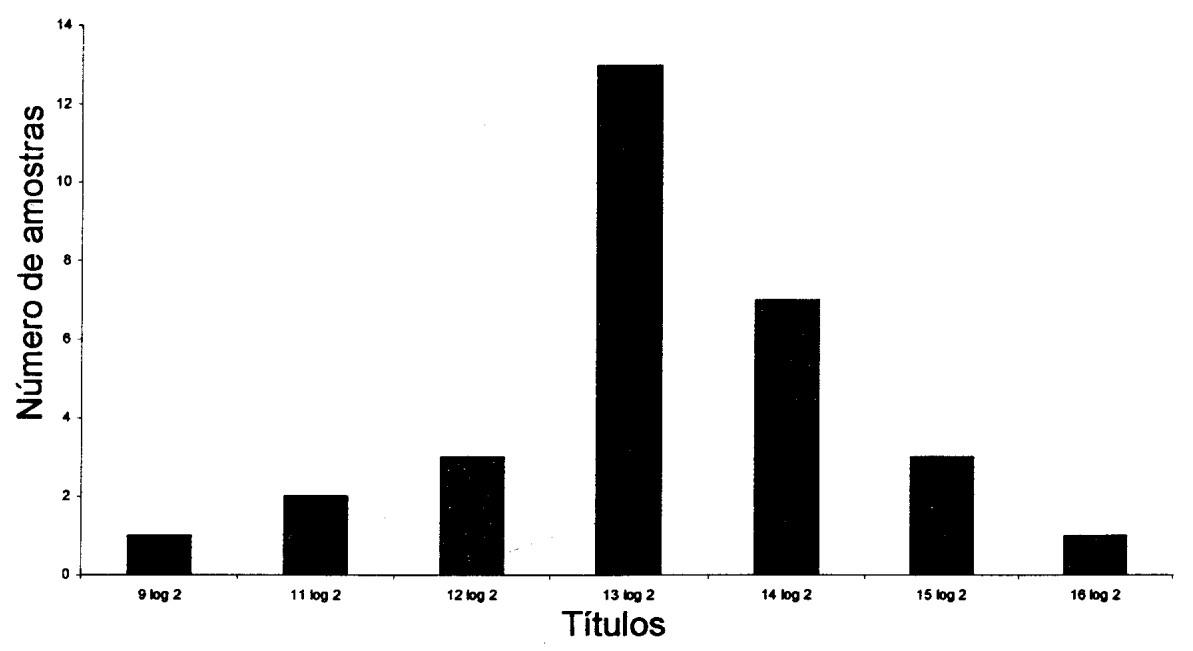

Figura 4 - Distribuição dos títulos de sangue ingerido em 30 exemplares de Lutzomyia longipalpis alimentadas em rato.

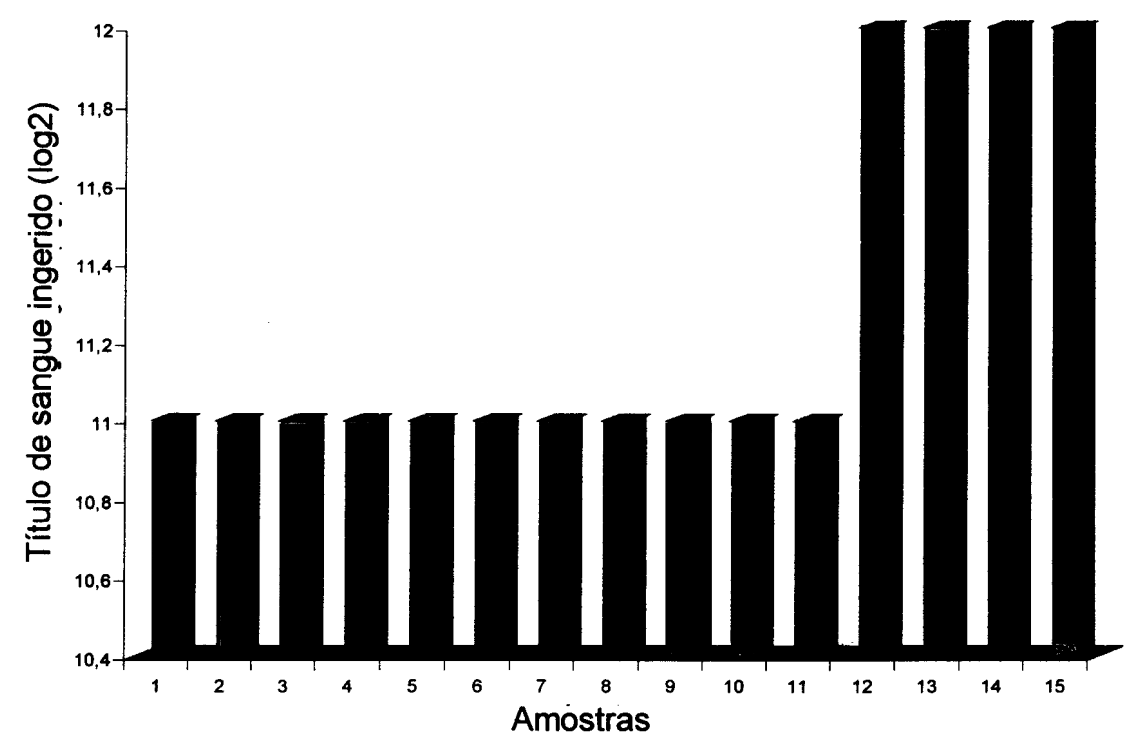

Figura 5 - Títulos de sangue ingerido por Lutzomyia longipalpis 12 horas pós-ingestão experimental em rato.

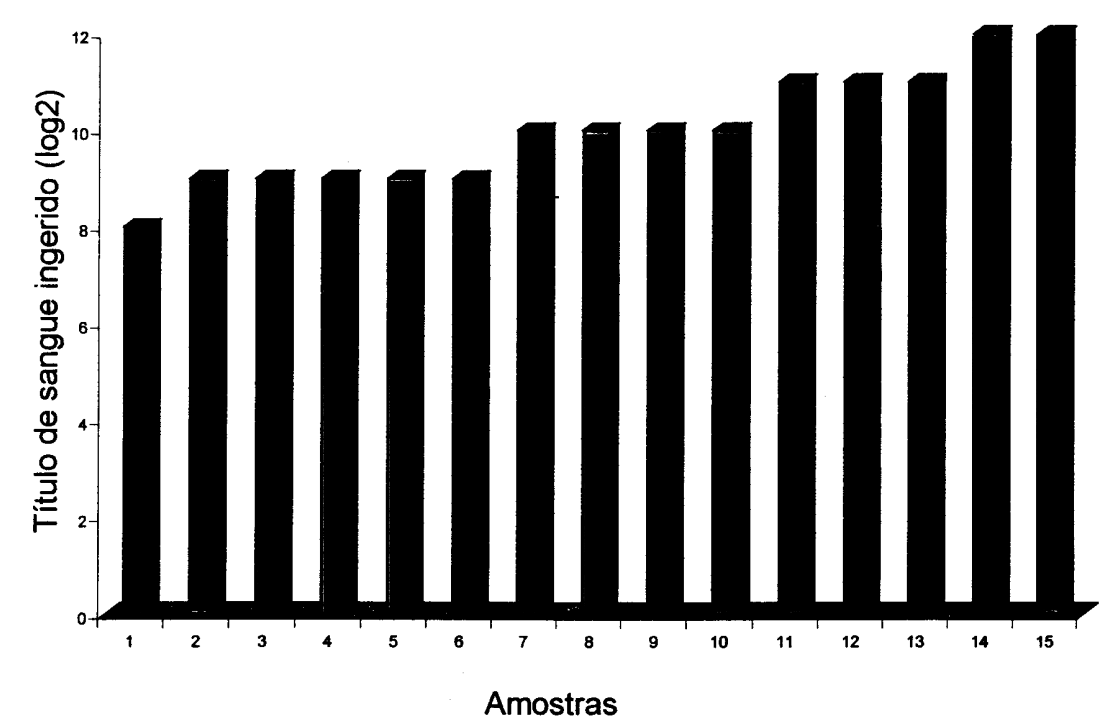

Figura 6 - Títulos de sangue ingerido por Lutzomyia longipalpis 24 horas pós-ingestão experimental em rato. 


\section{DISCUSSÃ0}

A atração de fêmeas de flebotomíneos em relação ao homem e animais domésticos tem sido alvo de vários estudos para a investigação da frequiência e especificidade do contato hospedeiro-vetor, que se reflete como fator de risco na transmissão das leishmanioses.

Embora 0 repasto sangüíneo para muitas espécies de flebotomíneos na Região Neotropical ocorra na população humana e de animais domésticos, torna-se de interesse, conhecer com que freqüência esta atividade se desenvolve em diferentes ecossistemas, para que se possa atribuir-lhes o papel de possíveis vetoras de Leishmania. Claro que, sendo os animais, hospedeiros essenciais das leishmanias, a multiplicidade destes com que 0 flebotomíneo se envolve, representa um importante determinante na epidemiologia das leishmanioses.

Com este enfoque, estudos valendo-se de iscas animais, têm fornecido dados essenciais, na resposta a questões das possíveis associações entre reservatórios e insetos transmissores, nos diferentes habitats ${ }^{367} .0$ mesmo não se pode afirmar em relação aos estudos de caráter experimental, como justificativa de identificação de preferência alimentar, visto que a fonte ao permanecer em contato com 0 vetor, induziria os repastos que, não necessariamente, seriam da forma como ocorrem na natureza ${ }^{9}$.

Portanto, 0 emprego de técnicas imunológicas no estudo do hábito alimentar associado ao hematofagismo de insetos pode acrescentar novos conhecimentos ao quadro epidemiológico de parasitoses, com a identificação de possíveis hospedeiros nos quais os agentes circulam, visto que cada vez mais têm-se observado a tendência da urbanização das leishmanioses.

Diferentes técnicas, mais tradicionalmente a de precipitina têm sido empregadas para a identificação de repastos sangüíneos de mosquitos e outros artrópodes hematófagos ${ }^{11}{ }^{14} 23$ e têm caracterizado o grupo hierárquico, tais como, ordens e classes de hospedeiros envolvidos no hematofagismo ${ }^{19}$.

O teste de precipitina é de utilização limitada para flebotomíneos, pois apenas cinco ou seis testes podem ser utilizados com sucesso, devido à pequena quantidade de sangue ingerido ${ }^{20}$. Embora sua execução seja relativamente simples, apresenta menor sensibilidade e especificidade e alto consumo de anti-soro.

Por outro lado, há algum tempo, diferentesmodalidadesda técnica imunoenzimática vêm sendo empregadas para a identificação dehábito alimentar de mosquitos ${ }^{2}$ com o objetivo de identificar a fonte sangǘnea dos possiveis reservatórios. Esta técnica tem se mostrado eficiente, por apresentar maior sensibilidade e especificidade, bem como a sua automação permitir o processamento e investigação de um grande número de amostras, o que representa um aspecto de importância na investigação epidemiológica.

Considerando que a sensibilidade e especificidade podem ser aumentadas com a introdução da técnica imunoenzimática de captura, Service e cols ${ }^{20}$ aplicaram esta metodologia para a identificação de sangue ingerido por culicídeos e culicóides e ressaltaram vantagens, como alternativa ao teste de precipitina, em vista da possibilidade de reconhecer a fonte sanguínea em amostras contendo quantidades reduzidas de sangue recém-ingerido.
Neste estudo, em relação aos trinta exemplares que apresentaram em torno de 2/4 a 4/4 de sangue no conteúdo abdominal e cujas amostras foram diluídas inicialmentea 1:256, o teste proveu a execução de aproximadamente noventa provas em duplicata. Desta maneira, utilizando 0 sistema fosfatase alcalina avidina-biotina foi demonstrado que com mínimas concentrações de soro total anti-rato $(0,625 \mu \mathrm{g} / \mathrm{ml})$, IgG conjugado à biotina $(8 \mu \mathrm{g} / \mathrm{ml})$ e com a diluição de avidina (1:40.000), foi possivel processar um grande número de amostras para a identificação de sangue ingerido, que numa pesquisa de campo é de extrema importância, quando não se dispõe de muitos recursos financeiros. Esta técnica também foi empregada com sucesso, no estudo dos possíveis mecanismosimunológicos envolvidos durante ainfecção e imunização de camundongos geneticamente modificados, com diferentes amostras de coronavirus ${ }^{21}$.

Ainda considerando as trinta amostras utilizadas, cujo conteúdo abdominal compreendia em torno de $2 / 4$ a 4/4 de sangue, a diluição inicial estabelecida foi de $5 \log _{2}(1: 256)$ e a reatividade pôde ser constatada a olho nú. Conforme se observa na Figura 4, a diluição de 1:8.192 que corresponde ao título de $13 \log _{2}$ foi a mais freqüente na amostragem em estudo, mas foram encontrados exemplares com diluiç̃oes até 1:16.384, 1:32.768, 1:65.536 que correspondem aos títulos de $14 \log _{2}, 15 \log _{2}$ e $16 \log _{2}$ 0 que suscita a alta sensibilidade do teste empregado.

Com base em nossa vivência, na grande maioria das vezes, observa-se em flebotomíneos capturados na natureza, aproximadamente dois a quatro quartos de sangue recém ingeridos no conteúdo abdominal, quantidade esta semelhante a utilizada neste experimento. Assim, 0 teste padronizado poderá ser empregado com sucesso na identificação de fonte alimentar.

Embora diferentes técnicas tenham sido empregadas para 0 estudo do hábito alimentar, as reagentes apontam para um curto período de tempo, aproximadamente 24 horas pósingestão ${ }^{118} 1920$.

Para 0 teste desenvolvido, a identificação de sangue ingerido foi viável para todos os exemplares de Lu longipalpis com até 12 e 24 horas pós-ingestão.

Considerando que a quantidade de sangue ingerido por culicídeos é sensivelmente superior à de flebotomíneos e culicóides, além das variáveis que podem influenciar nas taxas de digestão quantidade de sangue ingerido, temperatura ambiente, diferença entre exemplares da mesma espécie e entre espécies, idade fisiológica e fonte alimentar - os resultados obtidos neste estudo representam uma amostra da população para a qual o teste vem corresponder de maneira satisfatória, corroborando com os resultados encontrados pelos demais autores. Agradecimentos: Os autores agradecem à Dra. Ana Maria Moura da Silva pelas sugestões, ao Instituto Evandro Chagas pela doação dos espécimes de Lu. Longipalpis e à Maria das Graças Silva pela confecção das figuras.

\section{REFERÊNCIAS BIBLIOGRÁFICAS}

1. Blackwell A, Mordue AJL, Mordue W. Identification of bloodmeals of the Scottish biting midge, Culicoides impunctatus, by indirect enzyme-linked immunosorbent assay ( ELISA) . Medical and Veterinary Entomology 8: 20 24, 1994. 
2. Burkot TR, Goodman WG, Defoliart GR Identification of mosquito blood meals by enzyme-linked immunosorbent assay. American Journal of Tropical Medicine and Hygiene 30: 1336-1341, 1981.

3. Christensen HA, Herrer A. Attractiveness of sentinel animals to vectors of leishmaniasis in Panama. American Journal of Tropical Medicine and Hygiene 2: 578-584, 1973.

4. Colmenares M, Portús M, Botet J, Dobaño C, Gállego M, Wolff M, Seguí G. Identification of blood meals of Phlebotomus perniciosus (Diptera: Psychodidae) in Spain by a competitive enzyme-linked immunosorbent assay biotin/avidin method. Journal of Medical Entomology 32: 229-233, 1995

5. Comer JA, Irby WS, Kavanaugh DN. Hosts of Lutzomyia shannoni ( Diptera: Psychodidae) in relation to vesicular stomatitis virus on Ossabaw Island, Georgia, USA. Medical of Veterinary Entomology 8: 325-330, 1994.

6. Falqueto A. Especificidade alimentar de flebotomíneos em duas áreas endêmicas de Leishmaniose Tegumentar no Estado do Espírito Santo. Rio de Janeiro. Tese de Doutorado, Instituto Oswaldo Cruz, Fundação Oswaldo Cruz, Rio de Janeiro, RJ, 1995.

7. Gomes AC, Galati EAB. Aspectos ecológicos da leishmaniose tegumentar americana. 7- Capacidade vetorial flebotomínea em ambiente florestal primário do sistema da Serra do Mar, Região do Vale do Ribeira, Estado de São Paulo, Brasil. Revista de Saúde Pública 23: 136-142, 1989.

8. Guesdon JL, Ternynck T, Avrameas S. The use of avidin-biotin interaction in immunoenzymatic techniques. The Journal of Histochemistry and Cytochemistry 27: 1131-1139, 1979.

9. Guy MW, Killick-Kendrick R, Gill GS, Rioux J-A Bray RS. Ecology of leishmaniasis in the south of France. 19. Determination of the hosts of Phlebotomus ariasi Tonnoir, 1921 in the Cévennes by bloodmeal analyses. Annales de Parasitologie Humaine et Comparée 59: 449-458, 1984

10. King WV, Bull CG. The blood feeding habits of malaria-carrying mosquitoes. American Journal of Hygiene 3: 491-496, 1923.

11. Morrison AC, Ferro C, Tesh RB. Host preferences of the sandfly Lutzomyia longipalpis at an endemic focus of american visceral leishmaniasis in Colombia. American Journal of Tropical Medicine and Hygiene 49: 68-75, 1993.

12. Ngumbi PM, Lawyer PG, Johnson RN, Kilu G, Asiago C. Identification of phlebotomine sandfly bloodmeals from Baringo district, Kenya, by direct enzyme-linked immunosorbent assay (ELISA). Medical and Veterinary Entomology 6: 385-388, 1992.
13. Niebylski ML, Savage HM, Nasci RS, Craig Jr GB. Blood hosts of Aedes albopictus in the United States. Journal of the American Mosquito Control Association 10: 447-450, 1994.

14. Ogusuku BE, Perez JE, Paz L, Nieto E, Monje J, Guerra H. Identification of bloodmeal sources of Lutzomyia spp in Peru. Annals of Tropical Medicine and Parasitology 88: 329-335, 1994.

15. Porstmann T, Kiessig ST. Enzyme immunoassay techniques. An overview. Journal of Immunological Methods 150: 5-21, 1992.

16. Quinnell RJ, Dye C, Shaw JJ. Host preferences of the phlebotomine sandfly Lutzomyia longipalpis in Amazonian Brazil. Medical and Veterinary Entomology 6:195-200, 1992.

17. Rice JB, Barber AM. Malaria studies in Greece. A modification of the Ulenhuth-Weidanz precipitin test for determining the source of bloodmeals in mosquitoes and other insects. Journal of Laboratory and Clinical Medicine 20: 876-883,1935.

18. Rubio-Palis Y, Curtis CF, Gonzáles C, Wirtz RA. Host choice of anopheline mosquitoes in a malaria endemic area of western Venezuela. Medical and Veterinary Entomology 8: 275-280, 1994.

19. Savage HM, Niebylski ML, Smith GC, Mitchell CJ, Craig-Jr GBJ. Host-feeding patterns of Aedes albopictus (Diptera: Culicidae) at a temperate North American site. Journal of Medical Entomology 30: 27-34, 1993.

20. Service MW, Voller A, Bidwell DE. The enzyme-linked immunosorbent assay (ELISA) test for the identification of blood-meals of haematophagous insects. Bulletin of Entomological Research 76: 321-330, 1986.

21. Vassão RC, Consales CA, Sant'Anna AO, Pereira CA. Antibody responsiveness during immunization and challenge of genetically modified antibody responder mice with murine hepatitis virus 3. Immunobiology 207:1-9, 2003.

22. Voller A, Bidwell D, Huldt G, Engvall E. A microplate method of enzymelinked immunosorbent assay and its application to malaria. Bulletin of the World Health Organization 51: 209- 211, 1974.

23. Washino RK, Tempelis CH. Mosquito host bloodmeal identification: Methodology and data analysis. Annual Review of Entomology 28:179-201, 1983.

24. Yaghoobi-Ershadi MR, Javadian E, Kannani A. Host preference pattern of phlebotomine sandflies of Borkhar rural district, Isfahan province, Iran. Acta Tropica 60: 155-158, 1995.

25. Yolken RH. Enzyme immunoassays for the detection of infectious antigens in body fluids: current limitations and future prospects. Reviews of Infectious Diseases 4: 35-68, 1982. 